\title{
CAMINHOS E DESCAMINHOS DO DESEJO NOS TEXTOS DE EMMANUEL LÉVINAS E DE RENÉ GIRARD
}

Luiz Carlos Susin*

SINTESE - Este texto objetiva a comparação crítica entre o conjunto das obras de René Girard e Emmanuel Levinas no que diz respeito especialmente aos temas "desejo" e "contemporaneidade", evidenciando as formas diversificadas porém de certa forma convergentes pelas quais ambos os autores penetram na massa da fatos que podem se organizar reflexivamente nas estruturas mais profícuas de compreensão da realidade no atual momento histórico.

PALAVRAS-CHAVE - Desejo. Mímesis. Violência. Sacrificio. Ontologia.
ABSTRACT - This paper aims at providing a critical comparison of the works of René Girard and Emmanuel Levinas particularly as regards the issues of desire and contemporaneity, bringing to the fore the various but not altogether divergent ways in which the two authors see through the barrage of facts that may be reflectively organized as the most useful accounts of present-day reality.

KEY WORDS - Desire. Mimesis. Violence. Sacrifice. Ontology.

Ser "contemporâneo", como ser "conterrâneo", é uma aventura que se vive junto a outros como um apelo. Em diversas ocasiões, ao participar de diálogos e debates em clima de pluralismo, Lévinas se punha com esta intenção. Os contemporâneos vivem juntos sob os signos dos mesmos apelos, e isso pode se tornar um novo apelo, o ponto de partida para um diálogo fecundo dos diferentes. Lévinas e René Girard são contemporâneos desta "era dos extremos", e ambos experimentaram e tematizaram desde sua carne a perplexidade e a violência de nosso século, buscando, de forma inquieta, o caminho de saída e de superação. A minha intenção, aqui, é encontrar as afinidades e as diferenças nessa contemporaneidade de Lévinas e Girard. Numa publicação reunida em torno do pensamento de Lévinas, supondo algum conhecimento do mesmo por parte dos leitores, cuidarei de informar mais detalhadamente sobre R. Girard.

* Doutor. Professor da Faculdade de Teologia (FATEO) da PUCRS.

\begin{tabular}{|l|l|l|l|l|l|}
\hline VERITAS & Porto Alegre & v. 44 & n. 2 & Junho 1999 & p. 391-400 \\
\hline
\end{tabular}




\section{Biografias/bibliografias}

Lévinas retrata em sua vida um pouco da peregrinação do judeu errante, fazendo disso também pensamento e filosofia, partindo da Lituânia e encontrando na França as relações principais de sua biografia e de sua bibliografia, valorizando - Ocidente inaugurado pela clareza do logos grego, sem contudo idealizar ou se enraizar no "Ocidente" - horizonte do ocaso. René Girard, nascido em Avignon, à sombra de uma das páginas mais controvertidas da história da França e do Ocidente - a cristandade em conflito com o papado em Avignon, migrou para os Estados Unidos, onde encontrou a liberdade que a França, até por sua tradição universitária iluminista e positivista, quase necessariamente agnóstica em termos de fé, não lhe permitia facilmente. Mas também não decanta a american way of life. Ambos conheceram o impacto dos horrores da guerra mais central do século, a II Guerra Mundial. Lévinas a conheceu desde dentro, ao passar praticamente toda a guerra em um campo de soldados prisioneiros. René Girard já intuía e via nela o jogo violento do mimetismo do desejo entre as nações e a busca de vítimas expiatórias para a sua resolução.

Em termos de tradições religiosas, há uma coincidência de percurso não casual: Lévinas, tendo bebido com o leite materno a tradição marcadamente askenazita do judaísmo, viveu sua tradição e seu destino de ser judeu como que em segundo plano no tempo de sua formação filosófica, mas voltou vigorosamente à sua tradição em seu tempo de grandes intuições, exatamente no contraste com os acontecimentos da guerra. Girard teve uma infância católica, passando para um certo agnosticismo de sua formação acadêmica e seus primeiros ensaios, voltando-se de maneira cada vez mais central para a tradição bíblica e cristã nos últimos tempos, conduzido por uma espécie de redescoberta dos textos sagrados de sua tradição, especialmente dos evangelhos. Esse retorno, segundo suas palavras, foi conduzido por um espírito científico, em sua especialidade de crítico literário mas já também de antropólogo com uma teoria atordoante, a teoria do sacrificialismo. Levou-o à convicção de que se poderia provar cientificamente que as Escrituras contêm revelação divina.

Ambos, Lévinas e Girard, conheceram um desenraizamento de suas tradições na primeira fase de suas ampliações filosófica e literária. Ambos reencontraram de nova forma e com grande vigor as suas fontes, tornando-as centrais em seus escritos. Nenhum é sistemático ou apresenta clareza metodológica em sua bibliografia. São homens que escavam labirintos, dão golpes de marreta, fazem ensaios, perseguindo sempre uma intuição forte, desdobrando-a, tornando sempre a ela, erigindo-a em princípio heurístico e hermenêutico, em fundamento de uma teoria geral montada quase obsessivamente, como uma fonte de luz da qual surge sempre de novo, surpreendentemente, nova clareza, aclarando novas regiões ou regiões obscurecidas do conhecimento.

Tanto para Lévinas como para Girard se aplica claramente a tese de que, em pensamentos fortes e fecundos, a bibliografia está intimamente ligada à biografia. Eles são os "nomes próprios" que assinam com uma viva experiência os seus textos. $E$ como são contemporâneos, podemos assinalar alguns temas comuns com suas peculiaridades de enfoques. 


\section{No princípio é o desejo}

Tanto Lévinas como Girard voltaram sua atenção, o primeiro por caminho filosófico e o segundo por crítica literária, à categoria do desejo como expressão antropológica decisiva para expressar a relação ao outro. Ambos acabam incidindo em áreas da psicanálise, de Freud a Lacan, mas transversalmente apenas.

Lévinas tematiza o desejo de forma extremamente positiva, seguindo uma tendência da filosofia que tem nomes como Platão e Hegel. Exemplifica com a aspiração de Platão e rompe com a recondução do "outro" ao "mesmo" - ao selbst - no movimento dialético do desejo em Hegel. Em Totalité et Infini, Lévinas contrapõe desejo à necessidade, e isso lhe permite manter imaculada a positividade do desejo, enquanto Girard, mergulhado na literatura, expõe à luz a ambivalência obscura do desejo, ficando assim mais próximo da psicanálise.

Lévinas, guiado pela inspiração de Paul Valéry, que, por sua vez, lembra Platão, assume a categoria de desejo como uma aspiração pura, acima da necessidade, e sem mais correlação com a privação, aspiração que continua vigorosa mesmo depois e não obstante a satisfação e a abundância. Valéry o tinha denominado, seguindo Platão, de desejo sem defeito. E Lévinas o assume em seu discurso nessa direção. ${ }^{1}$

René Girard explora o triângulo do desejo, contestando a afirmação platônica de que é a bondade do objeto desejado que produz o desejo no desejante. Há uma questão anterior: como se apreende a bondade daquilo que se deseja? Quem ensina que algo é bom e, portanto, desejável? O outro, que também deseja. É o desejo do outro que imprime desejabilidade nos objetos de desejo. $\mathrm{Na}$ verdade, o objeto é apenas um lugar em que se consegue encontrar o desejo do outro, e é precisamente o desejo do outro que se deseja. Em direção à relação de desejo que o outro mantém com objetos de desejo é que se levanta o desejo. E o desejo que parte do outro, por sua vez, cruza com o desejo que o deseja, porque também é desejo de outro, de tal forma que, em útlima análise, os desejos se desejam como espelhos que se multiplicam ao infinito.

Não fazendo distinção de tipo levinasiano entre desejo e necessidade, Girard não distingue entre o "puro" e o "impuro", entre a transcendência que está na dinâmica do desejo suscitado pelo outro em sua positividade de outro - segundo Lévinas - e a imanência do desejo de ser o que o outro é, e que busca avidamente se abastecer do outro, ou seja, do seu desejo. $O$ desejo, na teoria girardiana, não se contém nem conhece a linha da necessidade. Pelo contrário, a tendência de Girard foi a de constatar no desejo o princípio da violência e da destruição pelo caminho da violação e da indiferenciação. Incide na sabedoria onipresente das religiões que se encerra no mandamento ou tabu fundamental: "não desejar". Só ultimamente Girard reconheceu a "naturalidade" pedagógica do desejo como que originalmente puro e bom, ao qual se deve positivamente a possibilidade de assumir as tradições, de aprender e de progredir. ${ }^{2} \mathrm{Na}$ realidade, porém, o desejo está como que contaminado por uma espécie de "pecado original" que é a mímesis, a

1 Cf. Humanisme de I' autre homme. Montpellier: Fata Morgana, 1972, p. 45.

2 Cf. Quand ces choses commenceront, s.l.: Arléa, 1994, p. 70-71. 
intenção de apropriação, que torna impura a admiração e a aspiração. A antropologia de Girard não permite ou só permitiria abstratamente a distinção entre desejo e necessidade. Neste mundo real, duro e caótico ao mesmo tempo, não há "outro" na sua pureza e "santidade" incontaminadas. A revelação divina consistirá na entrada desse "outro" puro e capaz de desmascarar os mecanismos da violência até o mais secreto do desejo, e este outro, que só pode ser divino, vindo "de fora" é Jesus - por isso mesmo ele é Messias.

\section{Mímesis e mesmificação}

Em Lévinas, toda a primeira parte de Totalité et Infini busca aclarar as categorias de "Mesmo" e "Outro". O Mesmo é produto da identidade do autón que totaliza e sintetiza em si mesmo, de diferentes modos, toda a realidade. Pelos verbos auxiliares - poder, ter, estar, permanecer, mas também saber, valer - e pelo modo de fruição, de apropriação, de potencialização, de abstração e teorização, há uma espécie de imolação da realidade, de todo "outro" à irresistível captação do Mesmo, que triunfa como idêntico, cada vez mais rico e glorioso, ao incorporar a si toda alteridade. Lévinas, na esteira de seu mestre Franz Rosenzweig, sobretudo inspirado por $A$ estrela da redenção, bate-se com a dialética hegeliana. Ao lembrar, na introdução a Totalité et Infini, o fragmento de Heráclito de que "a guerra é a verdade do ser", busca nas origens do pensamento dialético ocidental o que está na base e na consumação de toda dialética: a violência do imperialismo e da aniquilação. O conceito de "mesmidade" - a tão exaltada "identidade" que norteia a realização das pessoas, da política, da busca de liberdade e felicidade - e a sua deconstrução como quem quebra ídolos ou desmascara ideologias, pode ser considerado um passo forte e decisivo no pensamento crítico - pars destruens - de Lévinas.

Já René Girard, num texto considerado fundamental - $A$ violência e o sagra$d o^{3}$ - ataca reiteradamente, por análise de diferentes costumes culturais e em diferentes âmbitos literários, o fenômeno da mímesis onipresente em tabus, prescrições, ritos, leis e instituições, seja na forma de proibição, seja na forma de transgressão e seu séquito de conseqüências. Seu tratamento do desejo vem sempre acompanhado do qualificativo de mimético. O desejo porta consigo a dinâmica da mímesis. Antes de se colocar como um "ser de desejo", o humano se caracteriza por um "desejo de ser", um ex nihilo que se levanta como desejo, suscitado pelo outro, ou melhor, como já mencionei acima, pelo desejo do outro que, por sua vez, se levanta em direção de outrem, do próprio desejo que deseja o seu desejo. Essa relação ao desejo é anterior mesmo a alguma hipóstase inicial do círculo do autón em processos dialéticos de auto-identificação passanđo pelo héteron. É o seu nascimento do nada mas, ao mesmo tempo, a sua ansiosa busca de ancoradouro, de nutrição, de auto-realização.

Pode-se acompanhar os passos da teoria girardiana partindo do desejo mimético. O seu primeiro momento é exaltante: o outro é modelo de ser, mas, no fundo, modelo de desejo. A relação é pedagógica, aparece positivamente, pode ser con-

3 GIRARD, R. A violência e o sagrado. São Paulo: UNESP/Paz e Terra, 1990. 
fessada: deus é o outro. O desejo mesmo erige a divindade. Há algo de feuerbachiano na análise de Girard, mas com a força impressionante dos elementos de antropologia cultural e da literatura. E, antes de voar a uma divindade religiosa, a um ou vários espíritos ou entidades invisíveis, a força constituinte do desejo mimético pode ser constatada simplesmente nas relações humanas: o outro brilha, fascina, torna-se fonte de promessas, enfim é erigido em ídolo - modelo idealizado e confessado, ao qual se está disposto a pagar tributos para receber sua bênção, sua "energia", algo que dele passe ao seu devoto ou fã, adorador.

Há, porém, um segundo momento, em que a aproximação ao modelo, a infusão e confusão, portam a uma rivalidade destrutiva exatamente na culminância do desejo, quando a mimesis teria chegado à sua plenitude: o imitador acaba ocupando o espaço do seu imitado, absorvendo-o ou exigindo a inversão da relação e, na pior das hipóteses, destruindo-o. Mas então se inaugura, e sempre de novo, o caminho da destruição, do retorno ao caos através da indiferenciação, da violentação das diferenças pelo desejo mimético. Em Rei Édipo estão, para além da consciência dos seus atores, as diversas etapas dessa relação de "modelo-rival". René Girard critica Freud por ter explorado somente a segunda parte da tragédia, reduzindo-a a um parricídio, enquanto o seu começo está no pai-rei, Laio, que se previne contra o filho tentando eliminá-lo e criando um filho que é "filho do desejo" de solucionar a relação de "modelo-rival" pela eliminação do outro. A sexualidade, o tabu do incesto, o personagem da mãe-rainha, é apenas linguagem de um desejo mimético que tem sua origem no pai. Girard lamenta que Freud tenha esquecido Abraão, o pai que prefere salvar o filho perdendo seu próprio espaço e tornando-se um errante pela terra, e tenha se fixado, em termos de cultura judaica, em Moisés, como se a "lei" fosse o coração do judaismo, como se o pai sempre fosse "a lei". Nesse caso, ao invés de superar a lei para salvar a vida do filho, como fez Abraão, é necessário superar a lei contra o pai para chegar ao próprio espaço de maturidade humana, um espaço de poder disputado edipianamente. ${ }^{4}$ Este é apenas um exemplo literário entre os muitos analisados por Girard.

Seria possível relacionar o paralelismo antitético entre Laio-Édipo com Abraão-Isaac em Girard com o paralelismo também antitético entre Ulisses e Abraão em Lévinas: a figura de Ulisses representa bem a "pseudo-aventura" do Mesmo, da identidade que retorna a si mesma carregada das glórias que acumula em toda diferença sem se perder nessa viagem nostálgica. Abraão, no entanto, perde-se em cada passo, peregrino de uma obediência ab-soluta que chama para um caminho sem retorno, para uma a-ventura absoluta em que há prioridade $e$ assimetria de uma alteridade. A única identidade de Abraão, a única permanência em tal processo é a fidelidade que o responsabiliza por outro, que o obriga à vigilância e à confiança.

Hinkelammert, na esteira de Girard, explora o paralelismo entre Édipo e Cristo. Se Édipo é uma figura do fundamento do Ocidente, então, como todo alicerce, deveria permanecer escondido no subterrâneo. Sobre o seu drama é que se justifica o drama do Ocidente. Se Freud desvendou metade dele, é porque essa metade - o parricídio - já não sustenta a cultura ocidental. Mas a outra metade - o desejo

4 Cf. Ibidem, p. 91-114, 207-234. 
de filicídio de Laio - permanece semi-oculto apenas, pois foi um desejo que fracassou. Ora, o que Laio não conseguiu, segundo a teoria da satisfação vicária da redenção na teologia cristã, teria conseguido o Deus de Jesus: o pai envia o filho à morte sacrifical para aplacar todos os desejos, o de Deus que deseja a honra de seu nome conspurcado e os desejos humanos que desejam ser como deuses. E o filho, que aceita ser humano, aceita de modo supremo o sacrifício de si para aplacar o pai. Portanto, é Cristo o "Edipo Ocidental", segundo o título do precioso texto de Hinkelammert. ${ }^{5}$ Ou, como representa um velho missal romano, o que Deus não quis que Abraão fizesse, fê-lo o próprio Deus - o filicídio.

O filicídio é o ponto mais trágico da cultura que projeta até na divindade o aprisionamento na mímesis, na necessidade de defender a sua mesmidade e de se antecipar na solução do "modelo-rival". É como se toda cultura começasse onde os homens desejam ser deuses e onde os deuses. Lisonjeados por serem objetos de desejo, tomam suas providências em tempo para destruir a concretização de tal desejo. A idolatria é um modo de relações humanas. Ora, o Deus de Israel, sem nome e sem imagem, sem representação, recusa-se ao desejo mimético, recusa poder e sacrifício. Mas não se recusa a se aproximar como atmosfera e regaço de respiração, de nutrição e proteção, "misericórida e não sacrifício" onde há dom sem tributo, segundo a tradição dos profetas e do próprio Jesus. Isso é ruptura da mímesis e do círculo da mesmidade. Nesse sentido, o próprio Cristo dos evangelhos, do Novo Testamento deve ser interpretado à luz do desmascaramento dos mecanismos da mímesis e da revelação de uma pureza que inaugura outro modo de ser.

\section{Violência, sacrifício e ontologia}

A violência da totalização, tão fortemente denunciada por Lévinas, é a violência do "Mesmo", do autón que, por diferentes caminhos, por estratégias e artimanhas, conduz e reduz todo outro ao mesmo, à identidade gloriosa e vencedora de autón. Por fruição e absorção, por economização de um mercado total, politização de um Estado onipotente, ou mesmo abstração, conceitualização, ontologização e teorização universalizante, é sempre uma violência de quem, sujeito esconđido que subjuga e se erige em divindade, aplainando e igualando, homogeneiza a realidade enquanto submissão e subserviência. Lévinas parece um profeta incômodo que saltou para fora de seu ambiente judaico em que o nome dessa dinâmica de totalização seria idolatria, e falou em praças gregas, desmascarando a violência da razão, do logos ocidental, secularização da idolatria nos mitos religiosos e heróicos em que o herói, Ulisses grego ou a consciência moderna, se acorda e se levanta para realizar o que há de divino nele. Mas é sempre herói trágico, que acaba enredado na sua trama e se vê ultrapassado pelo dinamismo e pela lógica que ele mesmo desencadeou, acabando no redemoinho da violência própria dos deuses. Nessa linha se pode ver levinasianamente o sujeito moderno declinar de sua consciência com idéias claras e distintas, que o tornavam o sujeito forte da modernidade e da modernização na aventura de trazer o que é próprio do céu para

5 Cf. HINKELAMMERT, Franz. La fe de Abraham y el Edipo occidental. San José: DEI, 1989, p. 13-63. 
a terra, em sujeito soft, light, suave da pós-modernidade, consumido pelo seu próprio consumismo, no paradoxo de uma totalidade inteiramente complexa e impessoal, a do mercado reinante tecnologicamente, num ecossistema arruinado, transformado ainda romanticamente em possibilidade de ecoturismo, onde ecologias e culturas são fragmentadas e acolchoadas homogeneamente pela mesmidade do único príncipe, o mercado - terra tornada inferno pela desmedida de sua ambição de ser céu.

Os mais instigantes pensadores deste século dos extremos foram detetives da violência. Os três mais famosos mestres da suspeita, Marx, Freud, Nietzsche, detectaram violência respectivamente no atual estágio da burguesia imperante e alienante, na sexualidade reprimida pela culpa e expiação diante do "parricídio", na forma religiosa e mistificadora de esconder-se do próprio nada e da própria vocação heróica. Com as guerras nucleares de alta ou baixa intensidade, a violência se permitiu ser cada vez mais descarada porque cada vez mais segura de si. Daí a necessidade de escavar mais a fundo.

Lévinas detectou a violência na fabricação da ontologia que se erige em metafísica: a ontologia seria a secularização de uma idolatria, e a idolatria seria uma sacralização do interesse em totalizar. Porque porta o ser esta dinâmica de totalização, esse interessamento avassalador? Segundo a lição do conatus essendi, para se garantir em ser, penhorando e selando com sua marca de tal forma que sempre persevere e incremente seu ser - imortal em sua rigidez de monumento, de dito que aprisiona o dizer, de acabamento que pretende encerrar o infinito.

René Girard detecta a violência num vaivém da ordem que se rompe em direção a uma indiferenciação crescente produzindo o caos, e a violência que se impõe institucionalmente ao caos para fundar nova ordem e armar-se contra o caos. A violência da indiferenciação é a violência bandida que deve ser banida, do marginal e da periferia que precisam das forças da lei para reprimir com autoridade.

Como se consegue autoridade e lei num mundo em decomposição, numa ordem que se torna desordem? Seria o caos como que regenerativo por um passe de mágica, por um milagre? Seguindo as análises de Girard, a coisa é mais simples e mais trágica: a passagem da violência indiferenciada para a violência institucionalizada passa pelo fundamento que alicerça sem ele mesmo estar alicerçado, pelo herói que sustenta sobre si, como que pairando heroicamente sobre o caos, a ordem que se levanta sobre seu corpo imolado. O herói é, antes do reconhecimento do seu heroísmo, a figura expiatória que catalisa sobre si todas as violências, vítima sem culpa própria ou não proporcionalmente a alguma culpa pessoal, mas simplesmente como receptáculo de todas as violências, projetadas sobre a vítima-herói, passando-as de indiferenciadas a uma só violência, a violência "unânime" sobre a imolação e ereção de um fundamento sólido, o corpo-cadáver. Girard exemplifica de mil maneiras esse acontecimento crucial nas mais diferentes culturas.

A vítima expiatória pode ser comparada ao furúnculo que concentra a impureza de todo o corpo, arrasando um tecido mais frágil para descontaminar e provocar uma kathársis geral. Quando um povo bem articulado se desconjunta pela contaminação da indiferenciação do mimetismo, precisa de um phármakon, um 
ponto comum e unânime para descarregar a agressividade do caos onde as energias se batem e se entrelaçam, se entredevoram incapazes de uma ordem e uma ação ordenada. Portanto, o sacrifício de uma vítima expiatória - individual ou grupal, até um povo inteiro num genocídio mascarado pela justificativa de cruzada - é passagem do caos para o cosmo, é o fundamento do mundo, da ordem, das instituições, da cultura.

A teoria girardiana poderia ser resumida nesta afirmação: Toda cultura provém da religião e toda religião provém do sacrifício. ${ }^{6}$ A cultura, como uma espécie de superestrutura, se desdobra em tabus, proibições, organização da vingança, normas e leis, instituições, tradições e criações, mas com expressões e desejos fortemente policiados. Na sua base, no entanto, está a religião com seu modo sacro, divinizado, de elaborar prescrições na forma de memória que sustenta vivo o acontecimento do sacrifício expiatório, e de ritual - ação prescrita - que atualiza cuidadosamente o perigoso e decisivo momento do sacrifício fundador. Essa força da religião impregna ou banha com o sangue e o odor que exala do cadáver da vítima todo o corpo de tabus e leis positivas, tornando-as sacras, intocáveis e de autoridade indiscutível. Como também a seus guardiães e sacerdotes, os que sabem manipular o perigo do sacrifício.

No entanto, como em todo remédio homeopático, em que o próprio veneno do mal é convertido em veneno benéfico, é necessário que o sacrifício seja atenuado, bem medido e posto em ingrediente que o expanda beneficamente. Girard recorta longitudinalmente a evolução da humanidade em níveis sacrificais: o sacrifício de vidas humanas representativas - crianças inocentes, portadores de deficiências, jovens de beleza e integridade, inimigos ou chefes caídos em desgraça - passando depois para sacrifícios de outras criaturas, sobretudo animais com diferentes simbolismos humanos como formas substitutivas mais tênues. $O$ salto para a "misericórdia e não mais sacrifícios", com oferendas de louvor e ação de graças, é um estágio "evangélico", de certa forma até "escatológico".

A questão que retorna de dentro desta explicação girardiana é essa: como manter a ordem, o mundo instituído, sem o temor do castigo, sem o aparato da violência "pura" - judiciária, policial, moral, legal - que, afinal, é uma violência que se quer mais forte do que a violência caótica para não retornar à indiferenciação do caos, à violência "impura". Girard insiste: somente a misericórdia e não o sacrifício. Toda vez que se sacrificou os sacrificadores, que se tratou com intolerância os intolerantes, voltou-se sempre ao círculo dialético, fechado, da violência instituída que se corrompe em violência indiferenciada, exatamente aquela que pretendia evitar combatendo. Santo Agostinho, o jovem idealista que se tornou depois pastor e juiz de paz de uma Igreja turbulenta, ao invocar o "braço secular" com tremenda angústia, com justificativas e precauções para não se enredar na violência que estava invocando, tornou-se o paradoxo de uma referência para 0 retorno do sacrifício, das vítimas expiatórias em inquisições, fogueiras, cruzadas, guerras justas em nome do evangelho. Isso revela a complexidade e a delicadeza da questão.

6 Cf. a sintese de DEGUY, M., DUPUY, J.-P. René Girard et le problème du mal. Paris: Grasset, 1982, p. 103-108. Especialmente p. 105. 
Girard, apesar de sua piedade católica, não ameniza os equívocos do cristianismo histórico. Mas é com a modernidade e seu espírito científico que Girard mantém uma alta tensão sobre o abismo: a modernidade ousou desenterrar e tornar transparentes os alicerces que sustentam o mundo humano. Nunca a humanidade foi tão liberta de sacralizações e nunca perdeu tanta seriedade ao mesmo tempo, uma ambigüidade que, a ficar com o parágrafo final do seu clássico $A$ violência e o sagrado, estamos aptos ao saber completo - a ser como deuses - e ao mesmo tempo, paradoxalmente, à violência completa:

"Após termos emergido do sagrado mais completamente que as outras sociedades, a ponto de "esquecer" a violência fundadora, perdendo-a completamente de vista, vamos reencontrá-la. A violência essencial retorna sobre nós de forma espetacular, não somente no plano da história, mas no plano do saber. É por isso que esta crise nos convida, pela primeira vez, a violar o tabu que, no final de contas, nem Heráclito nem Eurípides violaram, tornando plenamente manifesto o papel da violência nas sociedades humanas numa ótica perfeitamente racional."

Lévinas, que é mais positivo no tratamento da categoria de desejo, elevando-a a uma categoria de relação metafísica com a alteridade, ao trabalhar as categorias de expiação e de substituição, onde estão embutidas imolação e sacrificio, toma também aqui uma direção mais positiva, um direcionamento ético. No tratamento dessas categorias emerge um Lévinas inteiramente identificado com sua tradição judaica, como quem fala desde dentro do que há de melhor em termos de "estrela da redenção", segundo o título da obra de Rosenzweig. É no clima da misericórdia mesma, segundo a etimologia hebraica - no ambiente do ventre maternal que geme em dores de parto - que se pode entender positivamente o sacrifício. É o mesmo que dom de si, possibilidade do autón, sua "conversão" de identidade identificadora e totalizante em resposta moral, responsabilidade e plataforma em auto-imolação na ética do serviço a outro. E todo serviço, toda decisão e responsabilidade de tornar-se servidor, é uma imolação, um sofrimento por quem faz sofrer, uma dor de maternidade que coincide com dor de nascividade de outro. É possibilidade, afinal, de morte por outro, morte substitutiva. Lévinas torna-se quase um místico da paciência ilimitada, da expiação e da substituição como responsabilidade por todos, ilimitadamente, e, exatamente nesse acontecimento ético que deborda a ontologia, ele vê a palavra que ilumina - profetiza, glorifica - quem pode suportar o universo. 8

Evidentemente a mesma realidade de violência, de poderes que se chocam, de imolação e de reconstrução, é visto por ambos desde pontos de vista muito diferentes, praticamente opostos. Girard examina e desmascara a maquinação dos processos vitimários, a sua sacralização e a fabricação de demônios e ídolos num mundo perversamente construído e sustentado. Vê a entrada de algo "que não é deste mundo" na revelação bíblica que, ao mesmo tempo que desmascara e desi-

7 Op. cit., p. 391.

8 Apresentei extensamente esta torsão da subjetividade em expiação e substituição, esse "messianismo" ao qual a subjetividade é convocada, passando de sujeito soberano a subjectum que suporta, em minha tese doutoral 0 homem messiânico - uma introdução ao pensamento de Emmanuel Lévinas. Porto Alegre: EST, 1984. 
dolatriza, resiste a entrar no círculo da violência retribuindo com o bem o mal recebido. Mas o que mais caracteriza Girard é a pars destruens com a força de um grande erudito em literatura e antropologia.

Lévinas, porém, partindo do âmbito da fenomenologia husserliana e da ontologia heideggeriana, é realista num ponto: num mundo de violências, para pacificar e reconciliar cada identidade na aceitação da alteridade e do pluralismo, quem poderia aceitar ser o ponto de torção, onde a agressividade totalizadora da identidade se dobre em piedade? Somente a subjetividade mesma - o eu - pode se oferecer. Isso não significa masoquismo de sangue derramado e nova violência, a da pregação de sacrifícios extremos, mas simplesmente a disposição ao serviço, a existência subjetiva como responsabilidade pelo mundo, por todo outro. De certa forma, a subjetividade, responsabilizando-se, descendo à profundidade de sua constituição mesma, fiel a si - ou seja, à dinâmica de uma relação anterior a si que a constitui - pode ocupar o lugar da vítima expiatória e sobrecarregar-se com o universo. Há uma abertura ética que abraça as estrelas, mas o agir é sempre mais local, de carne e osso, de fome e pão, de luta para que o outro seja e desinteressamento de si na oferta de si como serviço ao outro. Nisso consiste a unicidade, a diferença, a razão de ser, a liberdade mesma, em que a subjetividade revela - biblicamente falando - santidade.

Hinkelammert, ao falar de Cristo como "Édipo Ocidental", figura que foi interpretada como um filicídio divinizado e aceito filialmente - a famosa teoria feudal da satisfação vicária da redenção cristã - termina afirmando que Cristo é o enigma que o Ocidente ainda não conseguiu decifrar suficientemente, a figura com a qual ainda precisa se medir, pois até agora preferiu trazê-lo para dentro de seu círculo vitimário. René Girard conclui que é o seguimento de Cristo num amor irrecíproco, sem os limites do puro e do impuro, sem exigência para si, sem os castigos da lei, e numa vitória sobre a agressividade sem compactuar mas sem produzir novos vencidos, numa inteira gratuidade, que se revela ao mesmo tempo a face não violenta e inteiramente criadora de Deus e a vocação do humano.

Para quem escuta Girard e Lévinas, tem-se afinal a impressão de que o primeiro, um cristão, olha para o Messias que recompõe o mundo e a responsabilidade de segui-lo. E o segundo, um judeu passado pelo crivo da modernidade, olha para a responsabilidade humana como lugar de articulação do messianismo e do sentido do humano. 